\title{
Relation between body mechanics performance and nurses' exposure of work place risk factors on the low back pain prevalence
}

\author{
Yossria EL-Sayed Hossein*1, Hend Elham. Mohammed ${ }^{2}$, Amal H. Mohammed ${ }^{1}$ \\ ${ }^{1}$ Community Health Nursing, Faculty of Nursing, Minia University, Egypt \\ ${ }^{2}$ Medical Surgical Nursing, Faculty of Nursing, Minia University, Egypt
}

Received: August 7, 2018

DOI: $10.5430 /$ jnep.v9n3p25
Accepted: October 21, 2018

Online Published: November 11, 2018

\begin{abstract}
Background and objective: Low back pain (LBP) is a serious medical problem and considered as the most common leading causes of disability. Aim of the study: To measure the relation between body mechanics performance and nurses' exposure of work place risk factors on the low back pain prevalence.

Methods: Subject and method: Correlation design was used. A convenient sample of one hundred $(n=100)$ nurses both male and female working in Minia university hospital were approached to participate. Setting: The current study was performed at Minia university Hospital in Intensive Care Unit, Coronary Care Unit, Medical Care Unit, Stroke Care Unit, operation room and surgical department.

Results: The majority of nurses don't use body mechanics when turning, moving, lifting, and transferring the patients and $88 \%$ of them had pain in lumber region.

Conclusions and recommendation: The nurses' working in Minia university hospital suffering from high prevalence of LBP. The LBP complication is mainly related to exposure to many risk factors such as obesity, lack of knowledge and practice regard to body mechanics. Educational programs among nurses about body mechanics when handling and lifting the patient have important role in decrease exposure to LBP.
\end{abstract}

Key Words: Body mechanics, Nurses, Low back pain prevalence

\section{INTRODUCTION}

Lumbago or lumbosacral pain is accurate description of low back pain (LBP), which causes tension, discomfort, or even stiffness above the inferior gluteal folds and below the costal margin. ${ }^{[1]}$

LBP is one of the most common occupational health problems in nurses. ${ }^{[2]}$ The prevalence of LBP in nurses ranges between $40 \%$ and $97.9 \%$ and occurs more frequently in nurses when compared with other society individuals. ${ }^{[3]}$ The nurses performed many physically tasks in her job exposed them to LBP complication. ${ }^{[2]}$

The prevalence of musculoskeletal problems (MSP) among nurses is high $(7 \%-85 \%)$. The most common being in the lower back (56\%-57\%) and neck (52\%-56\%) regions. 60\%$61 \%$ of nurses experienced MSP in two or more body regions. The most significant risk factors for developing MSP were

\footnotetext{
* Correspondence: Yossria EL-Sayed Hossein; Email: yosria1968@yahoo.com; Address: Community Health Nursing, Faculty of Nursing, Minia University, Egypt.
} 
carrying weights and working in a forced position. The most important psychosocial risk factors were attributed to the fast pace and emotional demands of the work. Dissatisfaction with work and e.g. imbalance between work-family life conflicts also raised pain risk. ${ }^{[4]}$

Risk factors for LBP are multi factorial, including lack of exercise, obesity, smoking, higher age, and gender which all can be grouped together as individual risk factors. ${ }^{[5]}$ Other work-related lifestyle factors such as alcohol consumption and smoking may be considered as contributing factors to LBP. [6]

Nursing is well known to be one of the professions with the highest risk of LBP and there were also significant correlations between LBP and factors such as age, working hours per week, work experience, body mass index (BMI), gender and shift-work. ${ }^{[7,8]}$

Patient handling is considered as the most important risk factor for work-related LBP in nursing. ${ }^{[7]}$ Nursing students have extensive courses about safe patient handling in nursing schools through both clinical and theoretical basis. Nursing schools' responsibility is to adopt and apply proper body mechanics and effective patients' handling techniques which must be evidence-based protocol and manuals in everyday clinical practice. ${ }^{[9]}$

Understanding of proper body mechanics principles can be one reasonable way to prevent chronic back pain and to learn how to maintain correct ergonomics and vertebral posture during daily activities. In developed countries, significant improvements in staff behaviors and in creating supportive work facilities that have help them to prevent back pain. The prevalence of work-related musculoskeletal disorders among nurses can be reduced by ergonomics training of nurses about adequate body posture during nursing care. ${ }^{[10]}$

\section{Significance of the study}

The nurse is at risk every day to low back injuries while providing patient care, as nursing care may contain strenuous physical effort such as patient transferring in and out of bed during daily care. LBP is costly for both the nurse and the hospital costly, for the nurse as it results in pain, disability and hinder effective nursing performance, and costly for the hospital because the injured nurse is not able to provide the required level of nursing care and because treatment is costly.

In Egypt, low back pain affects nearly $60 \%$ of the country's population and nursing profession presents the highest prevalence of back work-related injuries compared with any other occupation. ${ }^{[11]}$

\section{SubJECTS AND METHODS}

\subsection{Aims of the study}

To measure the relation between body mechanics performance and nurses' exposure of work place risk factors on the low back pain prevalence.

\subsection{Research question}

Q1: What are the major contributing factors for LBP among nurses?

Q2: What is the nurses' knowledge about contributing risk factor for LBP?

Q3: What is the nurses' performance about body mechanics and its relation with $\mathrm{LBP}$ ?

\subsection{Research design}

Correlation design was applied to accomplish this study.

The preparatory phase included: The researchers made extensive review of both national and international literature through using various resources as books, articles, periodicals and journals. Necessary changes were carried out after completing the pilot study.

Panel of experts reviewed the tools for clarity, relevance, comprehensive understanding and applicability; a few modifications were made according to their opinion.

\subsection{Pilot study}

The researchers applied pilot study to test for clarity, completeness, validity, and practicability, the tools were completed by 10 nurses. Needed adjustemnts were made accordingly by the researchers. Nurses included in the pilot study were excluded from the actual study sample.

\subsection{Implementation phase}

The researchers started data collection from May 2017 to end of October 2017 after obtaining the permission to apply this study. The researchers visited the hospital to explain the aim of the study to nurses and to obtain their written consent to participate in this study. The tool was filled by researchers through face to face interview with each participant. The researcher met nurses at time convenient to them during their working schedule. Weight, height and body mass index were measured and calculate according to World Health Organization (WHO) requirements for all study nurses. The assessment of body mechanics observation checklist was carried out while the nurses were on duty during morning and afternoon shift. Each nurse was observed by the researchers one times at different duties. Nurses were observed two hours for each nurse, while they were performing nursing intervention for their patients during this period. Each nurse suffer from LBP assessed the level of pain by scale. 


\subsection{Setting}

The current study was conducted at different departments [Intensive Care Unit (ICU), Coronary Care Unit (CCU), Medical Care Unit (MCU), stroke Care Unit, operation room, and surgical department] at Minia university hospital in Egypt.

\subsection{Sample}

A purposive sample of nurses was taken from the previously mentioned study settings. The total number was one hundred nurses, both male and female who were working at the time of data collection were divided into 66 nurses from intensive care unit as ICU, CCU, MCU, stroke Care Unit, 6 nurses from operation room, 4 nurses from outpatient clinic and 24 nurses from different department as medical and surgical ward.

\subsection{Tools of data collection}

Data collection was done with the following tools:

\section{Tools I: Interview questionnaires sheet}

After reviewing the relevant literature, the researchers developed a construcetd questionnaire sheet and pilot tested before the study to assess nurse's knowledge regarding LBP risk factors and principles of body machanics to control back pain.

This questionnaire was used to assess nurses' knowledge about risk factors of LBP and principles of body machanics to control LBP. It also contained questions about sociodemographic data.

A-Socio demographic and health status data involved age, gender, qualification, years of experience, marital status, current and past history of LBP.

B-Assessment sheet for measuring weight and height and calculate the BMI according to the WHO (2003) classification: normal $\mathrm{BMI}=18.5-24.9 \mathrm{~kg} / \mathrm{M}^{2}$, overweight $\mathrm{BMI}=$ $25.0-29.9 \mathrm{~kg} / \mathrm{M}^{2}$, obesity $\mathrm{BMI}=30.0-39.9 \mathrm{~kg} / \mathrm{M}^{2}$ and the extreme obesity $\mathrm{BMI}=40.0 \mathrm{~kg} / \mathrm{M}^{2}$.

The part about nurses' knowledge regarding LBP contained information about nurses' knowledge about the contributing risk factors for LBP (8 questions) and nurses' knowledge about principles that reduce risk for development of LBP (10 questions)

The scores of each item ranged from " 0 " (= incorrect answer) to "1" (= correct answer). The total knowledge score was calculated by summation of all knowledge items with total score equal to 18 . Therefore the participants who would get $70 \%$ or more correct answers would be considered as having satisfactory level of knowledge, and if the participants would get less than $70 \%$ correct answers would be considered as Published by Sciedu Press having unsatisfactory level of knowledge.

The part about nurses' performance regarding body mechanics assessed through observational checklist was developed by researchers to assess malpractice during lifting and turning of the patients from bed.

The scores of each item ranged from " 1 " (= correct done) " 0 " (= not done) to or according to the complexity needed for intervention measures. Total score of observational checklist 71 steps.

\section{Tool II: McCaffrey initial pain assessment tool}

It was used to initial pain assessment regarding LBP it included description of pain characteristics (when pain start, quality, location, onset, frequency, duration, time of worse pain, difference in intensity with time, rhythm, tolerance, factors aggravating pain, pain management strategies)it was adopted from McCaffery et al. (1999). ${ }^{[12]}$

\subsection{Scoring systems}

LBP was assessed by Pain Intensity Scale. This scale is often displayed as a line numbered from zero to ten asking the nurse in pain to assign a number, from zero to ten according.

\subsection{Ethical consideration}

Oral consent obtained from each participant after explaining the nature \& objectives of the study to gain their cooperation. Each assessment sheet was coded and subjects' name was not appearing on the sheets for the purpose of anonymity and confidentiality. Subjects were free to end their participation from the study at any time.

\subsection{Administrative design}

An official letter was issued from the Dean of the Faculty of Nursing to the Directory of the Mina university hospital. Nurses' written informed consent for participation was obtained by the researchers' after explaining the aim of the study. Clarification of the nature and purpose of the study was done on initial interview with each nurse. The researcher emphasized that the participation was absolutely voluntary and that confidentiality as well as anonymity would be absolutely assured throughout the study.

\subsection{Statistical analysis}

Statistical analysis of data was done by using SPSS-21. The researchers analyzed, categorized and coded each tool. Qualitative and quantitative variables were represented in the form of frequencies and percentages and using means and standard deviations. Correlation statistical was done for assessing the inter-relationships among quantitative variables $p$ value $<.05$ was considered as statistically significant. 


\section{RESUlT}

Table 1 shows that, $52 \%$ of the study sample was females and $56 \%$ their age ranged from 21 to 30 years. Their educational level revealed that, around half had bachelor, $66 \%$ work at intensive care unit and $96 \%$ work as staff nurses and $90 \%$ are overweight.

Table 1. Demographic characteristics of the study sample (n $=100)$

\begin{tabular}{|c|c|c|}
\hline Items & No. $(n=100)$ & $\%$ \\
\hline \multicolumn{3}{|l|}{ Age } \\
\hline $21-<30$ years & 56 & 56.0 \\
\hline $30-<40$ years & 44 & 44.0 \\
\hline \multicolumn{3}{|l|}{ Mean \pm SD: $28.82 \pm 4.9$} \\
\hline \multicolumn{3}{|l|}{ Gender } \\
\hline Male & 48 & 48.0 \\
\hline Female & 52 & 52.0 \\
\hline \multicolumn{3}{|l|}{ Educational level } \\
\hline Diploma & 44 & 44.0 \\
\hline Bachelor & 50 & 50.0 \\
\hline Master & 6 & 6.0 \\
\hline \multicolumn{3}{|l|}{ Work place } \\
\hline Intensive Care Unit & 66 & 66.0 \\
\hline Inpatients unit & 24 & 24.0 \\
\hline Operating theater & 6 & 6.0 \\
\hline Outpatient clinic & 4 & 4.0 \\
\hline \multicolumn{3}{|l|}{ Job description } \\
\hline Head nurse & 4 & 4.0 \\
\hline Staff nurse & 96 & 96.0 \\
\hline \multicolumn{3}{|l|}{ Smoking } \\
\hline Smoker & 28 & 28.0 \\
\hline None smoker & 72 & 72.0 \\
\hline \multicolumn{3}{|l|}{ Body Mass Index } \\
\hline Normal BMI $=18.5-24.9 \mathrm{~kg} / \mathrm{M}^{2}$ & 4 & 4.0 \\
\hline Overweight BMI = 25.0-29.9 kg/M $\mathrm{M}^{2}$ & 90 & 90.0 \\
\hline Obesity BMI = 30.0-39.9 kg/M $\mathrm{M}^{2}$ & 6 & 6.0 \\
\hline Mean \pm SD: $24.25 \pm 3.1$ & & \\
\hline
\end{tabular}

Table 2 reveled that $58 \%$ of the study sample doesn't have a history of back pain before work. Forty four percent are working more than 56 hours per week and majority of sample reports have back pain related to work and work at night.

Table 3 illustrated the characteristics of pain the results revealed that $88 \%$ of them had pain in lumber region. $90 \%$ of them had gradual onset of LBP. More than two third of them $62 \%$ had aching pain. While $62 \%$ of studied nurses the pain worse in the evening. In relation to factors increase pain, the study revealed that majority of nurses $90 \%$ had LPB due to patient turning and positioning and $10 \%$ of them had LPB related to cold. In relation to factors decrease pain $40 \%$ of them reported medication relieved pain, while $20 \%$ of them mentioned support the back relieved LPB.
Table 2. Nurses job characteristics $(n=100)$

\begin{tabular}{lll}
\hline Items & No & $\%$ \\
\hline Past history of lower back pain before working & & \\
Yes & 42 & 42.0 \\
No & 58 & 58.0 \\
Current diseases causing back pain & & \\
Yes & 60 & 60.0 \\
No & 40 & 40.0 \\
Years of work experience as a nurse & & \\
1 - < 10 years & 72 & 72.0 \\
$11<20$ years & 24 & 24.0 \\
$21<30$ years & 4 & 4.0 \\
Mean \pm SD: $6.69 \pm 5.4$ & & \\
Working hours/week & & \\
36 - < 46 hours & 32 & 32.0 \\
46 - < 56 hours & 24 & 24.0 \\
$>56$ hours & 44 & 44.0 \\
Mean \pm SD: $28.82 \pm 4.9$ & & \\
Have night shifts & & \\
Yes & 88 & 88.0 \\
No & 12 & 12.0 \\
Back pain related to work & & \\
Yes & 84 & 84.0 \\
No & 16 & 16.0 \\
\hline
\end{tabular}

Table 4 shows that more than half of study subjects have unsatisfactory level of knowledge about risk factors and principle of body mechanic (57\% and $68 \%$ ) respectively.

Table 5 shows the majority of study subjects don't use body mechanic as turning, moving, lifting, positioning, moving and transferring the patients when caring for patients.

Table 6 shows that there is a positive significant correlation between back pain related to work and stress of work among the study subjects with a total score $r=.400$, at $p=.000$.

Table 7 shows that there is a positive significant correlation between back pain related to work and body mass index among the study subjects with a total score $r=-.282$, at $p=$ .004 .

Table 8 describes that there is a positive significant correlation between back pain related to work and duration of work among the study subjects with a total score $r=-.368$, at $p=$ .000 .

Table 9 shows that there is a positive significant correlation between knowledge and practices regarding LBP with a total score $r=.849$, at $p=.000$.

Table 10 shows that there is a positive significant correlation between LBP prevalence and body mechanics practice among the study subjects with a total score $r=.364$, at $p=$ .000 . 
Table 3. Pain assessment of LBP $(n=100)$

\begin{tabular}{|c|c|c|}
\hline Items & No. $(n=100)$ & $\%$ \\
\hline \multicolumn{3}{|l|}{ Location of pain } \\
\hline Cervical & 0 & 0 \\
\hline Lumber & 88 & 88.0 \\
\hline Sacral & 12 & 12.0 \\
\hline \multicolumn{3}{|l|}{ Onset of back pain } \\
\hline No & 0 & 00.0 \\
\hline Sudden & 10 & 10.0 \\
\hline Gradual & 90 & 90.0 \\
\hline \multicolumn{3}{|l|}{ Intensity of pain } \\
\hline No & 0 & 00.0 \\
\hline Mild & 50 & 50.0 \\
\hline Moderate & 38 & 38.0 \\
\hline Sever & 12 & 12.0 \\
\hline \multicolumn{3}{|l|}{ Duration of pain } \\
\hline Weeks & 50 & 50.0 \\
\hline Months & 38 & 38.0 \\
\hline Years & 12 & 12.0 \\
\hline \multicolumn{3}{|l|}{ Quality of pain } \\
\hline No & 0 & 00.0 \\
\hline Sharp & 18 & 18.0 \\
\hline Aching & 62 & 62.0 \\
\hline Shooting & 12 & 12.0 \\
\hline Sharp and aching & 8 & 8.00 \\
\hline \multicolumn{3}{|l|}{ Rhythmicity of back pain } \\
\hline Intermittent & 5 & 5.0 \\
\hline Nearly constant & 18 & 18.0 \\
\hline Constant & 48 & 48.0 \\
\hline After shifts & 29 & 29.0 \\
\hline \multicolumn{3}{|l|}{ Time of worse the pain } \\
\hline In the morning & 38 & 38.0 \\
\hline In the evening & 62 & 62.0 \\
\hline In the night & 0 & 00.0 \\
\hline \multicolumn{3}{|l|}{ Factors increase back pain } \\
\hline Cold & 10 & 10.0 \\
\hline Standing for long time & 24 & 24.0 \\
\hline Setting for long time & 28 & 28.0 \\
\hline Turning or lifting the patients & 38 & 38.0 \\
\hline \multicolumn{3}{|l|}{ Factors increase back pain } \\
\hline Warm compress & 10 & 10.0 \\
\hline Support the back & 20 & 20.0 \\
\hline Relaxation & 15 & 15.0 \\
\hline Message & 15 & 15.0 \\
\hline Medication & 40 & 40.0 \\
\hline \multicolumn{3}{|l|}{ Signs and symptoms } \\
\hline Nothing & 85 & 85.0 \\
\hline Nausea & 10 & 10.0 \\
\hline Dizziness & 5 & 5.0 \\
\hline
\end{tabular}

Figure 1 indicates that there is a positive significant relation between back pain and specialty among the study subjects with a total score chi $=.018$, at $p=004$.
Table 4. Knowledge regarding the risk factors of LBP and principles of body mechanics $(n=100)$

\begin{tabular}{lcc}
\hline Items & $\mathbf{N}$ & $\mathbf{\%}$ \\
\hline Nurse knowledge about risk factors that predisposing back \\
pain & 43 & 43.0 \\
Satisfactory & 57 & 57.0 \\
Un satisfactory & \multicolumn{2}{c}{} \\
Nurse knowledge about principles of body & mechanics to \\
control pain & 32 & 32.0 \\
Satisfactory & 68 & 68.0 \\
Un satisfactory & $3.25 \pm 2.4$ \\
Mean \pm SD & \multicolumn{2}{l}{}
\end{tabular}

Table 5. Practices of study subjects regarding body mechanic $(\mathrm{n}=100)$

\begin{tabular}{lll}
\hline Items & No & \% \\
\hline Lifting an object from a shelf above shoulder level & & \\
Done & 0 & 00.0 \\
Not done & 100 & 100.0 \\
Turning the patient toward you & & \\
$\quad$ Done & 2 & 2.0 \\
$\quad$ Not done & 98 & 98.0 \\
Turning the patient away from you & & \\
Done & 0 & 00.0 \\
Not done & 100 & 100.0 \\
Moving a patient up in bed & & \\
$\quad$ Done & 0 & 00.0 \\
$\quad$ Not done & 100 & 100.0 \\
Transferring a patient to stretcher & & \\
$\quad$ Done & 3 & 3.0 \\
$\quad$ Not done & 97 & 97.0 \\
Transferring a patient from bed to chair & & \\
Done & 10 & 10.0 \\
Not done & 90 & 90.0 \\
\hline
\end{tabular}

Table 6. Correlation between back pain related to work and work stress of the study subjects

\begin{tabular}{lcc}
\hline Item & $\boldsymbol{R}$-value & $\boldsymbol{p}$-value \\
\hline Back pain related to work & .400 & $.000^{* *}$ \\
Work stress & & \\
${ }^{* *} p<.01$ & &
\end{tabular}

Table 7. Correlation between back pains related to work and BMI of the study subjects

\begin{tabular}{lll}
\hline Item & $\boldsymbol{R}$-value & $\boldsymbol{p}$-value \\
\hline $\begin{array}{l}\text { Back pain related to work } \\
\text { BMI }\end{array}$ & -.282 & $.004^{* *}$ \\
\hline${ }^{* *} p<.01$ & & \\
\hline
\end{tabular}

Table 8. Correlation between back pain related to work and duration of work of the study subjects

\begin{tabular}{lll}
\hline Item & $\boldsymbol{R}$-value & $\boldsymbol{p}$-value \\
\hline Back pain related to work & -.368 & $.000^{* *}$ \\
Duration of work & & \\
\hline${ }^{* *} p<.01$ &
\end{tabular}


Table 9. Correlation between knowledge and practices of study subjects regarding LBP

\begin{tabular}{lll}
\hline Item & $\boldsymbol{R}$-value & $\boldsymbol{p}$-value \\
\hline Back pain related to work & .849 & $.000^{* *}$ \\
Practices & & \\
\hline${ }^{* *} p<.01$ & &
\end{tabular}

Table 10. Correlation between body mechanics practices of study subjects and LBP prevalence

\begin{tabular}{lll}
\hline Item & $\boldsymbol{R}$-value & $\boldsymbol{p}$-value \\
\hline LBP prevalence & .364 & $.000^{* *}$ \\
Body mechanics practice & & \\
\hline${ }^{* * p}<.01$ & &
\end{tabular}

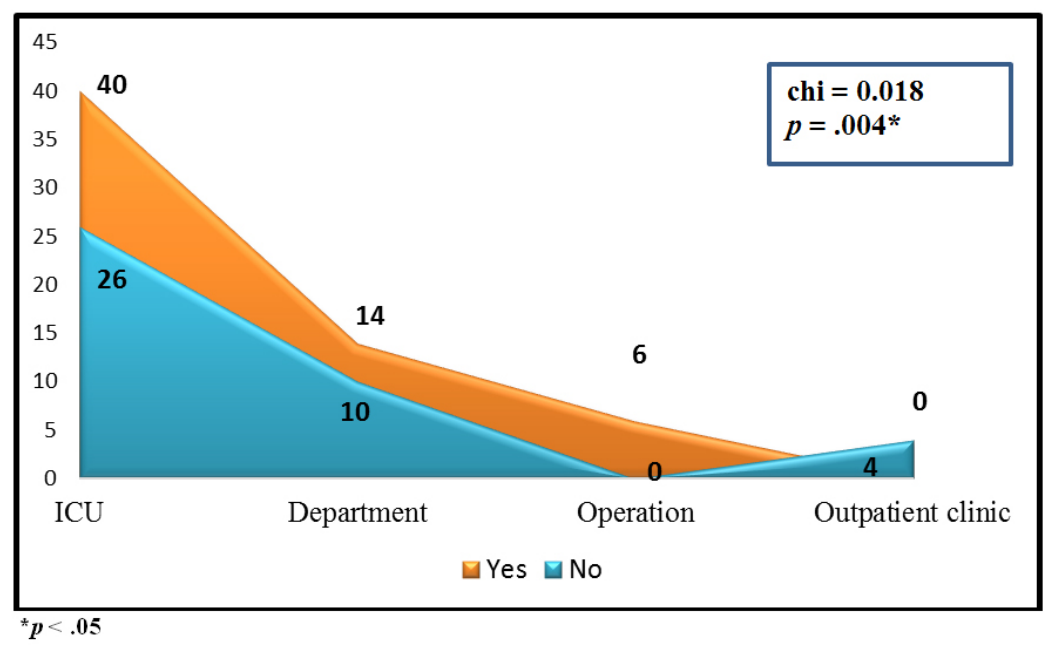

Figure 1. Relation between work area and suffering from back pain among study subjects

\section{Discussion}

Low back pain is considered as the most important contributing factor to number of years lived disabilities. Healthcare workers have remarkable high prevalence of LBP. ${ }^{[13]}$ Various nurses' responsibilities such as assisting patients' daily lives such as positioning them on the beds, carrying and lifting them also increase the risk of a low back trauma for nurses. ${ }^{[3]}$

The present study report that $90 \%$ of the nurses categorized as class I of obesity, this result of the study supported with El-Ghazaly et al. (2013) ${ }^{[14]}$ that add that in Egypt according to a study among nurses, the individual factors showed significant relation with LBP, which were age, marital status, and BMI.

Also the study by Boughattas et al. (2017) ${ }^{[15]}$ found high prevalence rate of LBP among Tunisian nurses. a regular physical activity and reducing nurses' overweight, as well as training them on proper patients' handling would help to reduce LBP.

The current research study showed that $50 \%$ of the nurses are suffering from mild LBP for weeks. As regarding factors increase pain $38 \%$ of study subjects feeling LBP when lifting and carrying the patient. As regard the best factor tolower the back pain, it was found that $40 \%$ of study subject uses medication.

These finding inconsistent with the result of Billis et al.
$(2017)^{[16]}$ who stated that the pain intensity of the nurse categorized from moderate to severe pain and lead to low of disability levels and this result agreement with the current study. Plus this author reports prevalence rate of back pain nearly over $40 \%$.

Also, Wannes et al. (2018) ${ }^{[17]}$ report the most properly consequences of LBP for nurses as work absenteeism, additional personal and economic costs, reduced nursing care efficiency, decreased quality of life, and even burnout. Unsurprisingly, several researches reported the association between workrelated LBP, nurses' negative beliefs, decreased job satisfaction and nursing burnout.

In additional, Abou El-Soud et al. (2014) ${ }^{[2]}$ report a strong association between LBP and the used postures in physical work as transferring patients and lifting heavy objects or equipment. Higher incidence of work-related back pain is remarkably present in developing countries due to shortage equipment and plan of work.

Also, many studies explored that many work factors area strongly correlated with the risk of LBP such as lifting of heavy object, frequent twisting and bending, and low job satisfaction. ${ }^{[18]}$

The finding of current study is in agreement with those of SeyedEhsan et al. (2017) ${ }^{[19]}$ who revealed nearly half of affected nurses receive medications in the form of Non- 
Steroidal Anti-inflammatory drugs (NSAIDS) and muscle relaxants, Also about one third receive physiotherapy, less than one third of the studied sample use topical preparations, while $14.28 \%$ of them required time off work, and only $5.88 \%$ need a back belt.

Finally, in the same line the study of Markus et al. $(2018)^{[20]}$ reported that recent systematic review about workplacebased interventions reported that physical exercise, especially resistance training is the most effective strategy for reducing and rehabilitating neck, shoulder and lower back pain.

The result of present study showed that more than half of study subjects have unsatisfactory level of knowledge about risk factors and principle of body mechanic (57\% and 68\%) respectively. This result agreement with that by Sikiru et al. (2010) ${ }^{[21]}$ who found that, the nurses' knowledge scores were insufficient, but can be increased when they are more experienced in nursing field, despite the lack of formal education.

Also, Sarallah et al. (2017) ${ }^{[10]}$ stated that many Iranian nursing assistants are not properly educated about the potential occupational hazard of work related LBP or about how to control and prevent such musculoskeletal disorders.

In addition, the result by Khudhir et al. (2017) ${ }^{[22]}$ added that the work related musculoskeletal disorders are the most contributing factors that cause occupational injury and nurses' disabilities. LBP can be reduced by certain prevention strategies and training courses with great emphasis on psychosocial risk factors and improving work environment. Finally, Boughattas et al. (2017) ${ }^{[15]}$ report that LBP is widely investigated in western countries, but in Tunisia, like in other countries perhaps, there is limited information about its' prevalence and risk factors.

The current study shows that there is majority of study subjects don't perform the body mechanics correctly, especially regarding turning, moving, lifting, positioning, moving and transferring the patients. This result is supported by those of Ibrahim \& Elsaay (2015) ${ }^{[11]}$ that revealed a highly statistically significant difference regarding total knowledge about back pain, body mechanics knowledge and performance preand post- program implementation.

The result of present study showed that there is positive significant correlation between LBP and work stress factors among the study subjects, which is in contrast with that of Yilmaz et al. (2012) ${ }^{[23]}$ that there reported that a LBP is positively associated with heavy physical work, frequent manual operations, repeated twisting of the trunk, whole body vibration and sitting for long time. Psychosocial factors, such as work demands, symptoms of stress and lack of social support have been reported to be important contributing factors of LBP.

The result of current research demonstrates that there is a positive significant correlation between back pain related to work and body mass index, this finding of current study agreement with Zingg and Kendalldo (2017) ${ }^{[24]}$ revealed that, LBP and obesity are both epidemics problem.

The current study results showed a positive significant correlation between back pain related to work and duration of work, this result is agreement with Shwn-HueyShieh et al. $(2016)^{[25]}$ who reported that with the increased number of cared patients per shift and longer daily working hours, it would lead to more musculoskeletal problems as LBP.

The current study shows that there is a positive significant correlation between knowledge and practices regarding body mechanics LBP. This result is supported with that by McCauley (2015) ${ }^{[26]}$ who stated that a nurse should have thorough scientific knowledge of body mechanics and its proper use in their daily practice.

\section{Limitation of the study}

Increase number of the study sample to ensure from accurate prevalence of LBP and assessment of body mechanics observational checklist were performed during morning and evening shift through heavy nursing duties.

\section{Conclusion}

The nurses' working in Minia university hospital suffering from high prevalence of LBP. The LBP complication is mainly related to exposure to many risk factors such as obesity, lack of knowledge and practice regard to body mechanics.

\section{Recommendation}

- Nurses should use the evidence-based strategy in prevention and management of LBP.

- Educational programs among nurses about body mechanics when handling and lifting the patient could be implemented to decrease exposure to LBP.

- Increase number of nursing staff in the same shift is important factor to reduce the occupational hazard.

\section{CONFLICTS OF INTEREST Disclosure}

The authors declare that there is no conflict of interest. 


\section{REFERENCES}

[1] American Academy of Family Physician. Diagnosis and treatment of acute low back pain. 2012. Available from: http://unmfm.pbwo rks.com/w/file/fetch/68529143/Diagnosis\%20and\%20tr eatment $\% 20$ of $\% 201$ ow $\% 20$ back\%20pain_AAFP.pdf

[2] Abou El-Soud AM, El-Najjar AR, El-Fattah NA, et al. Prevalence of low back pain in working nurses in Zagazig University Hospitals: an epidemiological study. Egypt Rheumatol Rehabil. 2014; 41: 109-15. https://doi.org/10.4103/1110-161X.140525

[3] Tosunoz IK, Oztunc G. Low Back Pain in Nurses. International Journal of Caring Sciences. 2017; 10(3): 1728.

[4] Freimann T. Musculoskeletal pain among nurses: prevalence, risk factors, and intervention. DSpace at University of Tartu. 2017.

[5] Hanan RA, Gehan HS. The effectiveness of the proposed range-ofmotion program on reducing sciatic pain [MD thesis]. Med J Cairo Univ. 2015; 28: 608-615.

[6] Heuch I, Hagen K, Heuch I, et al. The impact of body mass index on the prevalence of low back pain: the HUNT study. Spine (Phila Pa 1976). 2010; 35: 764-768. PMid:20228714 https://doi.org/10 .1097/BRS. Ob013e3181ba1531

[7] Yassi A, Lockhart K. Work-relatedness of low back pain in nursing personnel: A systematic review. International Journal of Occupational and Environmental Health. 2013; 19(3): 223-244. PMid:23885775 https://doi.org/10.1179/2049396713Y.00 00000027

[8] Samaei SE, Mostafaee M, Jafarpoor H, et al. Effects of patienthandling and individual factors on the prevalence of low back pain among nursing personnel. Work. 2017; 56(4): 551. PMid:28409765 https://doi .org/10.3233/WOR-172526

[9] Menzel N, Feng D, Doolen J. Low Back Pain in Student Nurses: Literature Review and Prospective Cohort Study. International Journal of Nursing Education Scholarship. 2016; 13(1): 1-21.

[10] Sarallah S, Tavafian SS, Jamshidi AR, et al. A Multidisciplinary Workplace Intervention for Chronic Low Back Pain among Nursing Assistants in Iran. Asian Spine J. 2017 Jun; 11(3): 419-426.

[11] Ibrahim R, Elsaay E. The Effect of Body Mechanics Training Program for Intensive Care Nurses in Reducing Low Back Pain. IOSR Journal of Nursing and Health Science (IOSR-JNHS). 2015; 4(5): 81-96.

[12] McCaffery M, Pasero C. Pain: Clinical manual, St. Louis, Mosby; 1999.

[13] Holtermann A. Implementation of a resident handling programme and low back pain in elder care workers. Occup Environ Med. 2016.

[14] El-Ghazaly AM, Gadallah HA, El-Gaafary MM, et al. Prevalenceand risk factors of low back pain among nurses in Ain Shams University Hospitals [MD Thesis]. Egyptian Rheumatol Rehabil J. 2013; 11: 55-90.
[15] Boughattas W, El Maalel O, Maoua M, et al. Low Back Pain among Nurses: Prevalence, and Occupational Risk Factors. Occupational Diseases and Environmental Medicine. 2017; 5: 26-37. https://doi.org/10.4236/odem.2017.51003

[16] Billis E, Koutsojannis C, Matzaroglou C, et al. Associationof low back pain on physical, sociodemographic and lifestyle factores across a general population sample within Greece. Journal of Back and Musculoskeletal Rehabilitation. 2017; 30(2): 279-290. PMid:27689603 https : //doi.org/10.3233/BMR-150484

[17] WannesHoofa W, Sullivanb K, Keeffe M, et al. The efficacy of interventions for low back pain in nurses: A systematic review. International Journal of Nursing Studies. 2018; 77: 222-231. PMid:29121556 https ://doi.org/10.1016/j.ijnurstu. 201 7.10 .015

[18] Eriksen W, Bruusgaard D, Knardahl S. Work factors as predictors of intense or disabling low back pain; a prospective study of nurses' aides. Occupational and Environmental Medicine. 2004; 61: 398-404. https://doi .org/10.1136/oem. 2003.008482

[19] Seyed E, Mahrous OA, Shaheen HM, et al. Low back pain among attendants to a Family Health Center in El-Dakahlia governorate, Egypt. Menoufia Med J. 2017; 30: 28-33. https://doi .org/10 .4103/mmj.mmj_170_16

[20] Markus D, Sundstrup E, Brandt M, et al. Effect of physical exercise on musculoskeletal pain in multiple body regions among healthcare workers: Secondary analysis of a cluster randomized controlled trial. Musculoskeletal Science and Practice. 2018.

[21] Sikiru B, Akodu AK, Oyeyemi AL. Work-related musculoskeletal disorders among Nigerian Physiotherapists. BMC Musculo skeletal Disorder. 2010; 9: 112.

[22] Khudhir K, Saleh K, Qadir M, et al. Association Between WorkRelate Musculoskeletal Disorder and Ergonomic Risk Factors Among Nursing Professionals in Ranya and Qaladiza Districts. Kurdistan Journal of Applied Research. 2017; 2(2): 65-70. https : //doi .or g/10.24017/science.2017.2.25

[23] Yilmaz E, Dedeli O. effect of physical and psychosocial factors on occupational low back pain. Health Science Journal. 2012; 6(4).

[24] Zingg RW, Kendal R. Obesity, Vascular Disease, and Lumbar Disk Degeneration: Associations of Comorbidities in Low Back Pain. American Academy of Physical Medicine and Rehabilitation. 2017; 9(4): 398-402.

[25] Shieh SH, Tavafian SS, Jamshidi AR, et al. A Multidisciplinary Workplace Intervention for Chronic Low Back Pain among Nursing Assistants in Iran. Asian Spine J. 2016; 11(3): 419-426.

[26] McCauley M. The Effect of Body Mechanics Instruction on Work Performance among Young Workers. Am Occup Ther. 1990; 44(5): 402-7. https://doi.org/10.5014/ajot.44.5.402 